\title{
Regulatory advancements in plant protection
}

\author{
R.M. Fisher \\ Market Access Solutionz, PO Box 10629, Wellington 6021, New Zealand
Corresponding author: Rebecca@solutionz.co.nz
}

In 2011 the Ministry for Primary Industries Sustainable Farming Fund (SFF) project 'Registration of sustainable agrichemicals for minor crops' was initiated. This project brought together 12 grower groups (both fruit and vegetables), six agrichemical companies and the Government Regulator to address the issue of registration of agrichemicals for minor crops. SFF funding was used in conjunction with industry funds and chemical company in kind contributions to develop and refine registration policy to make it more achievable, efficient and economically viable for minor crop groups to register agrichemicals. There are a number of international initiatives and policies aimed at reducing the barriers to agrichemical registration of minor crops. In order to make registration economically viable for NZ minor crops, regulator acceptance of the following policies were tested:

- Extension to an existing crop group - this is where a representative crop is used to gain a label claim for the whole crop group. For example, a product registered on head lettuce (a major crop) can be extended by conducting two trials on leafy vegetables to apply for a label claim to cover the whole 'leafy vegetable' crop group.

- Data substitution - this is using international data to reduce the required number of NZ residue trials. One project involved up to 50\% data substitution where there were no residues in the crop (registration was gained for squash by carrying out only two trials instead of three stated in the residue standard). Another project involved 100\% data substitution in a covered crop (greenhouse fruiting vegetables) where overseas data were presented instead of NZ trials.

- Residue extrapolation - this is where extrapolation is used from a currently registered crop to another within the same crop group where there are no residues in the crops. For example potato residue data were used to gain a registration in kumara as both of these crops are in the root and tuber crop group.

- Facilitation of claims using a global joint review data package. This reduces the need for NZ residue trials by using global trial data and grants a generic Good Agricultural Practice (GAP; defined as using the minimum quantity of agrichemical necessary to achieve adequate control, applied in a manner so as to leave a residue which is the smallest amount practicable). For example, a new active was granted a claim for multiple vegetable crop groups using a global data package.

The regulator approved registrations utilising these polices thereby establishing precedents. These policies may not have previously been tested and this public project has allowed communication of how others can successfully achieve registrations for minor crops. In addition to the registration projects, five different crop trials were carried out to establish residue decay curve data to allow informed off label use to enable growers to meet default or set MRLs. The confirmation of these policies provides a framework for minor crop groups to utilise these principals when undertaking future trials. This means that future registrations for minor crops should be more economically viable (i.e. as the cost of data generation is reduced). Growers can continue producing quality crops and will have access to more sustainable agrichemicals. As a result of the project, NZ is a key contributor in minor crop international policy advancement and has formed closer relationships with groups facing similar issues globally. Linkages with the minor crops programmes internationally have been established (particular with the USA, 
Canada and Australia) and strengthened throughout this project. This is a very important outcome as it will enable international collaboration on future projects. Chemical companies are committed to the project and are enthusiastic about the achievements. Linkages developed through this project will have flow-on effects to other developments for crop groups that were not part of the SFF project. Additional industry groups have expressed strong interest in joining the project in its next phase. This project ended in June 2015 and has been extremely successful with outcomes including agrichemical registrations of at least ten new claims for minor crops. The streamlining of the registration process has reduced reliance on older, less sustainable agrichemicals and provided alternatives to compounds being phased out. Agrichemical decay curve guidance developed as a result of trials carried out on vegetable crops has allowed informed off label use. This project was designed to develop and refine regulatory policy and make it easier to achieve registrations for minor crops. It is necessary to continue to build on these minor crop plant protection advancements. As a result, consideration is being given to extending this project to include more crop groups on a longer term basis. Coordination of a minor crops programme for NZ will ensure that the participants (minor crop groups, chemical companies and the regulator) continue to work together to ensure the availability of sustainable agrichemicals for all horticultural crops. Sources of funding for the next phase of the project will be a focus in the future. 